\section{Efficacy of topical photody- namic therapy in the treatment of Erythroplasia of Queyrat}

\author{
Massimo Iafrate, ${ }^{1}$ Mariangela Mancini, ${ }^{1}$ \\ Tommaso Prayer Galetti, ${ }^{1}$ \\ Serena Szekely, ${ }^{2}$ Edoardo Zattra, ${ }^{2}$ \\ Daniele Vaccari, ${ }^{2}$ Stefano Piaserico ${ }^{2}$ \\ ${ }^{1}$ Urology Clinic, Department of Surgery, \\ Oncology and Gastroenterology - \\ Urology Clinic, University of Padua; \\ ${ }^{2}$ Unit of Dermatology, Department of \\ Medicine, University of Padova, Padua, \\ Italy
}

\begin{abstract}
Erythroplasia of Queyrat (EQ) is an intraepidermal carcinoma in situ presenting clinically as a sharply demarcated, slightly raised erythematosus plaque on the glans penis or the inner side of the foreskin. Various treatment modalities for EQ have been proposed, including electrocautery and curettage, topical 5-floururacil cream, imiquimod cream, isotretinoin, cryotherapy, laser therapy, radiotherapy, ingenol mebutate gel and Photodynamic Therapy (PDT). Most of these treatments are limited by low clearance rates and frequent relapses. Surgical treatment including local excision, Mohs micrographic surgery and partial or total penectomy, ensures adequate healing rates. However, discomfort consequent to surgical treatment might be unacceptable. Topical PDT using the methyl ester of 5aminolaevulinic acid (MAL) is an established non-surgical treatment of cutaneous precancerous lesions and skin cancers. We present the case of a 60-year-old uncircumcised man affected by EQ of the penis successfully treated with MAL-PDT, performed five times, two weeks apart, with no recurrences after 6 years.
\end{abstract}

\section{Introduction}

Queyrat first described four patients with persistent reddish plaques on the glans penis $^{1}$ and named this condition "erythroplasia”. Erythroplasia of Queyrat (EQ) is an intraepidermal carcinoma in situ presenting clinically as a sharply demarcated, slightly raised erythematous patch on the glans penis or the inner side of the foreskin. ${ }^{2}$ Redness, crusting, bleeding, pain, scaling, ulceration, and discharge may also be present. $80-90 \%$ of reported cases of EQ are usually seen in uncircumcised men. ${ }^{3}$ Dermoscopy is typical and consists of the presence of structureless pink areas and a vascular pattern comprised of clustered dotted or glomerular vessels; scale, scar-like areas and erosions are also observed. ${ }^{4}$

EQ carries a risk of progression in invasive squamous cell carcinoma (SCC) in 10$33 \%$ of cases. $^{3}$ Topical Photodynamic Therapy (PDT) using the methyl ester of 5aminolaevulinic acid (MAL) is an established non-surgical treatment of cutaneous precancerous lesions and skin cancers. ${ }^{5}$ This therapy involves a photodynamic reaction characterized by a photochemical process involving the generation of reactive oxygen species following the absorption of light by a photosensitizer. We present a case of EQ successfully treated with MAL-PDT.

\section{Case Report}

A 60-year-old uncircumcised man presented with an erythematous lesion on the glans penis with velvety surface and net margins (Figure 1). The lesion was asymptomatic but the patient complained mild bleeding after sexual activity. A biopsy was performed revealing an acanthotic thickened epidermis, numerous atypical keratinocytes, mitoses at different levels, multinucleate and dyskeratotic keratinocytes with a chronic inflammatory infiltrate in the subjacent dermis. Therefore, the pathologist confirmed the clinical diagnose of EQ.

The lesion was treated with MAL-PDT. Methyl aminolevulinate $(160 \mathrm{mg} / \mathrm{g})$ cream was applied $1-\mathrm{mm}$ thick in the affected area with 5 millimetres of surrounding apparently healthy skin and occluded with transparent medical dressing manufactured by $3 \mathrm{M}$ (Tegaderm) and a white gauze dressing to block ambient light. One hour before the illumination, the patients received $100 \mathrm{mg}$ tramadol to reduce pain during the treatment. After three hours, medication was removed and the area was cleaned with saline solution. Then we performed the irradiation, using a red light delivered by an incoherent light emitting diodes source (Aktilite, Galderma, France) with an emission spectrum peak of $633 \mathrm{~nm}$ and a narrow bandwidth of $30 \mathrm{~nm}$ at a dose of $40 \mathrm{~J} / \mathrm{cm}^{2}$ for 7 minutes and 40 seconds. We positioned the lamp at a distance of $5 \mathrm{~cm}$ from the skin surface. A fan and sprayed cool water was used to reduce pain during illumination. The treatment was performed five times, two weeks apart. The patient complained intense pain during the irradiation and severe swelling and redness the subsequent days (Figure 2). After three months of therapy a complete response was obtained and no clinical recurrences were noted during the following 6 years of follow up (Figure 3).
Correspondence: Massimo Iafrate, Department of Surgery, Oncology and Gastroenterology - Urology Clinic, University of Padua, Via Giustiniani 2, 35128, Padua, Italy.

Tel.: +390498218752 -Fax: +390498212721

E-mail: massimo.iafrate@unipd.it

Key words: Erythroplasia of Queyrat, carcinoma in situ, photodynamic therapy

Conflict of interests: The authors have no conflict of interest to disclose.

Received for publication: 2 April 2020.

Accepted for publication: 24 May 2020.

This work is licensed under a Creative Commons Attribution-NonCommercial 4.0 International License (CC BY-NC 4.0).

(C) Copyright: the Author(s), 2020

Licensee PAGEPress, Italy

Dermatology Reports 2020; 12:8566

doi:10.4081/dr.2020.8566

\section{Discussion}

Erythroplasia of Queyrat (EQ) is a carcinoma in situ of the penis mostly seen in uncircumcised man. Clinically, it appears like an erythematous lesion with smooth surface and net margins. EQ and Bowen's Disease (BD) are both premalignant lesions but EQ has a greater tendency to progress to SCC. ${ }^{3}$ Biopsy is essential to confirm diagnose and to exclude invasive growth. Various treatment modalities for EQ have been proposed, including electrocautery and curettage, topical 5 -floururacil cream, ${ }^{6}$ imiquimod cream, ${ }^{7}$ isotretinoin, ${ }^{8}$ cryotherapy, ${ }^{9}$ laser therapy, ${ }^{10}$ radiotherapy, ${ }^{11}$ ingenol mebutate gel (but recently suspended by EMA). ${ }^{12}$ Most of these treatments are limited by low clearance rates and frequent relapses. Surgical treatment includes local excision, Mohs micrographic surgery ${ }^{13}$ and partial or total penectomy..$^{14}$ PDT is a treatment approved in Europe for superficial basal cell carcinoma, actinic keratoses and BD. During PDT treatment, malignant and premalignant cells are destroyed selectively as demonstrated by the tumor: normal skin fluorescence ratio of $15: 1.5,15$ The usefulness of PDT (ALA or MAL) in the treatment of EQ is rather uncertain. Few reports described the use of topical PDT in the treatment of EQ. ${ }^{15-18}$

Topical PDT can be chosen either because of a previous failure of topical therapy, for example imiquimod or 5-fluorouracil, or in case of recurrence after surgery, or when the patient is reluctant to undergo a surgical intervention. 
Published data reported good responses, with only a few patients showing progression of the disease or not being able to tolerate the therapy. Most patients experienced erythema and burning during illumination, following by mild swelling. Adverse effects included erythema, pain, burning, discomfort associated with dysuria, local haematoma, painful inflammatory reaction, erosion/ulceration blistering, dyschromia, hyperpigmentation. ${ }^{16-19}$

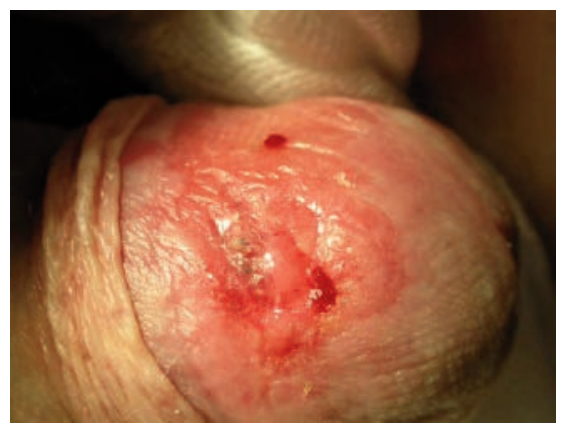

Figure 1. Erythroplasia of Queyrat of the penis; baseline.

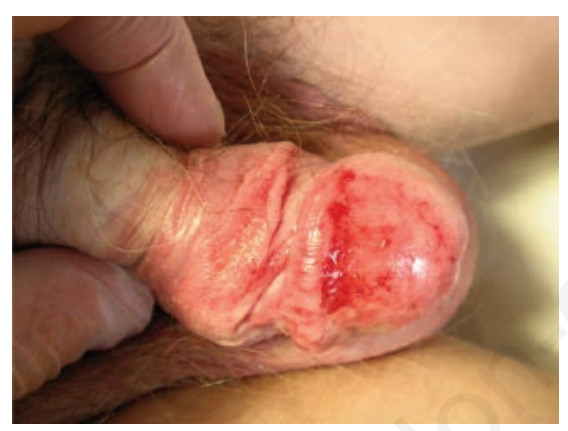

Figure 2. Severe phototoxic reaction with swelling, redness and pain; three days after the irradiation.

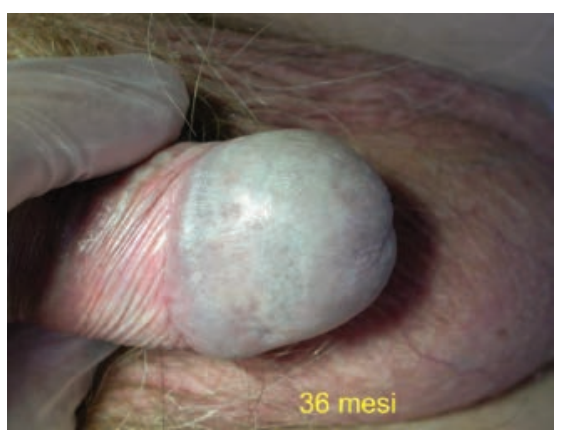

Figure 3. Clearance of the lesion and no recurrence after 36 months.

\section{Conclusion}

Our case of a EQ successfully treated with MAL-PDT provides further support to the use of this approach in the management of EQ. We achieved a complete response with an excellent cosmetic result, and, remarkably, no clinical recurrence after 6 years. The licensed use of MAL-PDT for BCC and Bowen's disease recommends two sessions, one week apart. We decided to perform MAL-PDT with an interval of two weeks between sessions because of the persistence of an intense phototoxic reaction lasting 10-15 days after the irradiation. The additional clinical benefit with treatment continuation to 5 sessions suggests the need of an aggressive protocol, with a higher number of sessions than the conventional use for BCC and Bowen's disease.

\section{References}

1. Queyrat L. Erythroplasie du gland. Bull Soc Fr Dermatol Syphiligr 1911;22:378-82.

2. Stamm AW, Kobashi KC, Stefanovic KB. Urologic Dermatology: A Review. Curr Urol Rep 2017;18:62.

3. Nägeli MC, Ramelyte E, Dummer R. Cutaneous squamous cell carcinomas on special locations: perioral, periocular and genital area. J Eur Acad Dermatol Venereol 2019;33:21-4.

4. Errichetti E, Lallas A, Di Stefani A, et al. Accuracy of dermoscopy in distinguishing erythroplasia of Queyrat from common forms of chronic balanitis: results from a multicentric observational study. J Eur Acad Dermatol Venereol 2019;33:966-72.

5. Morton CA, Szeimies RM, BassetSeguin N, at al. European Dermatology Forum guidelines on topical photodynamic therapy 2019 Part 1: treatment delivery and established indications actinic keratoses, Bowen's disease and basal cell carcinomas. J Eur Acad Dermatol Venereol 2019;33:2225-38.

6. Antônio JR, Antônio CR, Trídico LA, Alves FT, Rollemberg I. Erythroplasia of Queyrat treated with topical 5-fluorouracil. An Bras Dermatol. 2016;91:42-4.

7. Yokoyama M, Egawa G, Makino T, Egawa K. Erythroplasia of Queyrat treated with imiquimod 5\% cream: The necessity of regimen guidelines. Clin Case Rep. 2019;7:723-5.

8. Harrington KJ, Price PM, Fry L, Witherow RO. Erythroplasia of Queyrat treated with isotretinoin. Lancet
1993;342:994-5.

9. Shaw KS, Nguyen GH, Lacouture M, Deng L. Combination of imiquimod with cryotherapy in the treatment of penile intraepithelial neoplasia. JAAD Case Rep 2017;3:546-9.

10. Torelli T, Catanzaro MA, Nicolai N, et al. Treatment of Carcinoma in situ of the Glans Penis with Topical Imiquimod Followed by Carbon Dioxide Laser Excision. Clin Genitourin Cancer 2017;15:e483-7.

11. Panizzon RG. Radiotherapy of skin tumors. Recent Results. Cancer Res 2002;160:234-9.

12. Proietti I, Michelini S, Skroza N, et al. Ingenol mebutate therapy in erythroplasia of Queyrat: a new approach. G Ital Dermatol Venereol. 2019. doi: 10.23736/S0392-0488.19.06371-5.

13. Mohs FE, Snow SN, Larson PO. Mohs micrographic surgery for penile tumors. Urol Clin North Am 1992;19:291-304.

14. Hanash KA, Furlow WL, Utz DC, Harrison EG Jr. Carcinoma of the penis: a clinicopathologic study. J Urol 1970;104:291-7.

15. Skroza N, La Viola G, Pampena R, at al. Erythroplasia of Queyrat treated with methyl aminolevulinate-photodynamic therapy. G Ital Dermatol Venereol 2020;155:103-6.

16. Feldmeyer L, Krausz-Enderlin V, Töndury B, at al. Methylaminolaevulinic acid photodynamic therapy in the treatment of erythroplasia of Queyrat. Dermatology 2011;223:52-6.

17. Fai D, Romano I, Cassano N, Vena GA. Methyl-aminolevulinate photodynamic therapy for the treatment of erythroplasia of Queyrat in 23 patients. J Dermatolog Treat 2012;23:330-2.

18. Maranda EL, Nguyen AH, Lim VM, Shah VV, Jimenez JJ. Erythroplasia of Queyrat treated by laser and light modalities: a systematic review. Lasers Med Sci 2016;31:1971-6.

19. Calzavara-Pinton PG, Rossi MT, Aronson E, Sala R, Italian Group For Photodynamic Therapy. A retrospective analysis of real-life practice of off-label photodynamic therapy using methyl aminolevulinate (MAL-PDT) in 20 Italian dermatology departments. Part 2: oncologic and infectious indications. Photochem Photobiol Sci 2013;12:15865. 